\title{
Optimal Stock, Harvest and Effort Level of Bangladesh Trawl Shrimp Fishery - A Nonlinear Dynamic Approach
}

\author{
M. SHAMIM UDDIN KHAN ${ }^{*}$ \\ Department of Finance and Banking, University of Chittagong, Chittagong, Bangladesh
}

\begin{abstract}
The purpose of this paper is to develop a non-linear dynamic model for Bangladesh trawl shrimp fishery for optimal control in discrete-time frame. The model has been developed on the concept of optimal resource management based on the criterion of maximization of present values of net economic revenues. The results of the optimal steady state solutions (i.e. optimal stock, harvest and effort level) for ensuring long run sustainability of the resource through the model are presented. Results reveal that Bangladesh marine shrimp fishery is not managed and utilized optimally. Present condition of high effort level, less harvest amount and less shrimp stock indicates that the danger of depletion of the resource cannot be ruled out.
\end{abstract}

Key words: Bangladesh marine shrimp fishery, optimal management, non-linear dynamic model.

\section{INTRODUCTION}

International experience has shown that overfishing, as a result of improper management of fishing, may cause extinction or near extinction of different species of fishes, like Antarctic blue whales (FAO, 1979), Antarctic fin whales (FAO, 1979), Hokkaido herring (Murphy, 1977), Peruvian anchoveta (Johnston and Suiten, 1996), Southwest African pilchard (Butterworth, 1980), North Sea herring (Saville, 1980), California sardine (Murphy, 1977), Georges Bank herring (Sinderman, 1979), Japanese sardine (Murphy, 1977), and Canadian cod fishery (Ruitenbeck, 1996) etc. However, many other factors other than mismanaged fishery may also have contributed to the collapse of these species, like - change in temperature and salinity, reduced food abundance etc. But over estimation of biomass, high levels of juvenile catch, underestimation of fish mortality etc. that led to overexploitation of a species and its collapse are manifestation of mismanaged fishing scenario.

The practice of the management of renewable resources has generally been relied on the concept of Maximum Sustainable Yield (MSY). The concept of MSY suggests exploiting the surplus production on the basis of biological growth model. Several objections have been raised against the use of MSY on both biological and socioeconomic grounds. One of such serious objections is obviously the non-recognition of cost-factor. Recognition of the inadequacy of MSY concept has resulted in a trend to replace it with a concept of optimal resource management based on criterion of maximization of present values of net economic revenues. However, Bangladesh Marine Trawl shrimp fishery is managed at present on the basis of MSY concept.

\footnotetext{
* Corresponding author: Asstt. Professor, Dept. of Finance and Banking, CU, E-mail: shamimukhan@yahoo.com

(C) 2006 School of Agriculture and Rural Development, Bangladesh Open University, All rights reserved.
} 
Bangladesh has a land area of 1,47,570 sq. km. and has declared an Exclusive Economic Zone (EEZ) from her base line to 200 nautical miles seaward in 1974. As a result along with 710 $\mathrm{km}$. (coast line) an area of about 1,66,000 sq. km., which is greater than actual land of Bangladesh, is now under the economic jurisdiction of the country for exploitation, exploration, conservation, and management of its living and non-living resources (DOF, 1999). At present the marine fisheries sector contributes about $22 \%$ of the country's total fish production. Several surveys have been conducted in Bangladesh marine waters to assess, particularly the demersal fish/shrimp resources. Result of these surveys differs significantly estimation-to-estimation starting from 1,550 metric tons shrimp to 11,400 metric tons shrimp (West, 1973; Saetre, 1981; Penn, 1983; Rashid, 1983; Khan et al, 1983; White and Khan, 1985; VanZalinge, 1986; and Lamboeuf, 1987).

Bangladesh Marine fishery has two sub sectors, such as artisanal fishery and industrial (trawl) fishery. Trawl shrimp fishing is one of the most important sectors in marine fishing in Bangladesh with respect to foreign exchange earnings, employment etc. Bangladesh started with a fleet of 10 trawlers after liberation i.e. 1972-1973. The numbers of trawlers more than doubled to 21 in a year and then jumped to 26 two years later. The current number of trawlers is 119 of which 41 are shrimp trawlers and the remaining are fish trawlers (BBS, 1999; MFSMUC, 2007). The trawlers operate in the shelf area beyond the depth of 40 meters in the EEZ. The effort in the trawl fishery during the last two decades have been rotated around 5,000-6,000 standard fishing days to produce $3,500-6,000$ metric tons of shrimp. This is, however, no agreement on MSY of penaeid shrimp of Bangladesh. The MSY of penaeid shrimp is estimated as 7,000-8,000 metric tons and the optimum effort for producing the said amount is 7,000-8,000 standard days (BOBP, 1997). Other estimations of MSY of penaeid shrimp are 4145 metric tons (using Schaefer model) and 4329 metric tons (using Fox model) (Khan and Hoque, 2000). Because of an unplanned and irrational increase in fishing efforts, many species of the marine fish and shrimp stocks have already been declined (Khan and Hoque, 2000a; Khan, 2000). As a result, coastal fishing has become non-remunerative and fisher folk are becoming poorer. Their fruitless endeavor for survival is thus putting more and more damaging pressure on the resources.

In this paper, we have attempted to formulate a non-linear dynamic model of Bangladesh trawl shrimp fishery for optimal control with discrete-time. We have also attempted to estimate the optimal steady state solution (i.e. optimal stock, harvest and effort level) through the model that ensures the long run sustainability of the resource, maximum benefit and excludes the possibility of depletion due to overexploitation.

\section{MATERIALS AND METHODS}

\section{Sources of Data and Methodology}

We have used published data of (i) BOBP (1993; 1997), (ii) Department of Fisheries (DOF, 2000), (iii) Marine Fisheries Survey Management Unit Chittagong (MFSMUC, 2007), Bangladesh, for the time series data of harvest and effort for the period 1981-1982 to 2005-2006. Due to unavailability of time series data on dock-price of commercially exploited trawl shrimp, we have used published data of Export Promotion Bureau of Bangladesh (EPBB, 2000) for time-series data of exported shrimp price. The data from sample survey made by Khan and Hoque (2000) are used for estimation of cost parameters. We have solved the nonlinear dynamic optimization model with discrete time through Microsoft Excel.

\section{The Model}

We assume that one of the objectives of the shrimp fishery is that it should be managed to maximize the discounted present value of net benefit over time. In case of Bangladesh trawl shrimp fishery we propose the following non-linear dynamic programming problem, which maximizes the objective function of present value of net benefit (PVNB) over the time period $(0, T)$ with discrete uniform time interval, subject to usual constraint of growth function. 
Maximize

$$
\left.\begin{array}{c}
\text { PVNB }=\sum_{t=0}^{T} \beta^{t} . \Pi\left(x_{t}, h_{t}\right) \\
\text { Subject to, } \\
x_{t+1}-x_{t}=f\left(x_{t}\right)-h_{t} \\
f\left(x_{t}\right)=\frac{d x}{d t}=r x_{t}\left(1-\frac{x_{t}}{K}\right) \\
x_{0} \text { (given) } \\
\text { and } x_{t}, h_{t} \geq 0
\end{array}\right\}
$$

Here $\Pi($.$) is a concave profit function expressed in terms of harvest, stock level, \beta=\frac{1}{1+\delta}$ is a social discount factor and ' $\delta$ ' is social discount rate; ' $r$ ' denotes the intrinsic growth rate; ' $K$ ' denotes the saturation level or carrying capacity; and ' $h_{\mathbf{t}}$ ' denotes the harvest level at period ' $\mathbf{t}$ '. Symbol ' $x_{t}$ ' denotes biomass level at period ' $t$ ', which follows logistic growth function or surplus production function.

Net benefit $\Pi($.$) is calculated as total revenue less total operating cost. We have assumed that$ cost function is an increasing function of harvest and decreasing function of biomass. Thus,

$$
\Pi(x, h)=p(h) . h-C(x, h)
$$

where $p(h)$ is demand function and $C(x, h)$ is total effort cost.

\section{Solution of the Model for Optimum Allocation}

The dynamic formulation of our problem defined in (1), takes the form following the procedure suggested by Conard (1999):

$$
\begin{aligned}
& \text { Maximize } \\
& \begin{aligned}
\text { PVNB }= & \Sigma \beta^{t} \cdot \Pi\left(x_{t}, h_{t}\right)+\frac{\beta^{t} \Pi\left(x_{t+1}, f\left(x_{t+1}\right)\right.}{\delta} \\
\text { Subject } & \text { to } \\
& x_{t+1}-x_{t}=f\left(x_{t}\right)-h_{t} \\
& x_{0} \text { (given) }
\end{aligned}
\end{aligned}
$$

Following are additional characteristics of above system:

(i) In each period, escapement stock or what remains after harvest enters the growth schedule. The value of intrinsic growth rate $(\mathbf{r})$ and carrying capacity or saturation level $(\mathbf{K})$ which are estimated by Ray and Khan (2003) are given by $r=1.330818$ and $K=11400$ metric tons.

(ii) The model assumes deterministic logistic growth function of a single species (penaeid shrimp).

(iii) We assume that demand is linear in price and stationary, the inverse demand or willing to pay (WTP) function of harvest $\mathbf{h}$ is $\mathbf{p}(\mathbf{h})=\mathbf{d}_{\mathbf{1}}+\mathbf{d}_{\mathbf{2}}$. $\mathbf{h}$. We estimate inverse demand function by using price and harvest data through ordinary least squares method and get estimates $\mathbf{d}_{\mathbf{1}}=10,759.389$ and $\mathbf{d}_{\mathbf{2}}=-0.69602$.

(iv) The harvest cost varies with harvestable stock (measured prior to harvest) and harvest. The cost function is as $c(x, h)=\frac{c_{2} h}{q^{u}}$,

where the values of $\mathbf{c}_{2}=1156.76$, estimated by Khan and Hoque (2000) on the basis of sample survey during 1999. We have used $\mathbf{q}=0.0000977332$, estimated by Ray and Khan (2003), and $\mathbf{u}$ is assumed to be unity. 
(v) The social discount rate $(\delta)$ is assumed to be 0.1

(vi) Producers are competitive.

We, therefore, try to solve dynamic allocation problem objective of which is to find approach path which maximizes objective function (PVNB). Hence industry's profit in period ' $t$ ' is given by the explicit function,

$$
\begin{aligned}
\pi\left(x_{t}, h_{t}\right)=p\left(h_{t}\right) \cdot h_{t}-C\left(x_{t}, h_{t}\right) \\
=d_{1} h_{t}-d_{2} \cdot h_{t}{ }^{2}-\frac{c_{2} h_{t}}{q x_{t}}
\end{aligned}
$$

Substituting this explicit profit function in the objective function of (3), we obtain,

$$
\begin{aligned}
\sum_{t=0}^{t} \beta^{t}\left(d_{1} h_{t}-d_{2} h_{t}^{2}-\frac{c_{2} h_{t}}{q x_{t}}\right)+\frac{\beta^{t}}{\delta}\left[d_{1} r x_{t}\left(1-\frac{x_{t}}{K}\right)\right. \\
\left.-d_{2} r^{2} x_{t}^{2}\left(1-\frac{x_{t}}{K}\right)^{2}-\frac{c_{2} r x_{t}}{q x_{t}}\left(1-\frac{x_{t}}{K}\right)\right]
\end{aligned}
$$

Using the objective function (5), optimal steady state or optimal levels of harvest and stock are determined by solving the problem (3). The optimal level of stock $\left(\mathbf{x}^{\star}\right)$ and harvest $\left(\mathbf{h}^{\star}\right)$ in each year gives optimal level of effort and shadow price for each year of our study period by using following standard equations (Clark, 1990; Conard, 1999):

Effort, $E^{*}=h^{*} / q x^{*}$, where $q=$ catchability co-efficient,

and shadow price, $\lambda^{*}=(1+\delta)\left[p-c_{2} / q x^{*}\right]$, where $p=$ price of shrimp.

\begin{tabular}{|c|c|c|c|c|c|c|}
\hline Year & $\begin{array}{c}\begin{array}{c}\text { Actual } \\
\text { Stock } \\
\text { (tons) }\end{array} \\
\end{array}$ & $\begin{array}{c}\text { Optimal } \\
\text { Stock } \\
\text { (tons) } \\
\end{array}$ & $\begin{array}{c}\text { Actual } \\
\text { Harvest } \\
\text { (tons) }\end{array}$ & $\begin{array}{c}\text { Optimal } \\
\text { Harvest } \\
\text { (tons) }\end{array}$ & $\begin{array}{c}\text { Actual } \\
\text { Effort } \\
\text { (days) } \\
\end{array}$ & $\begin{array}{c}\text { Optimal } \\
\text { Effort (days) }\end{array}$ \\
\hline 1981-82 & 4592.00 & $4,592.00$ & 1697 & $2,480.81$ & 3782 & 5527.76 \\
\hline $1982-83$ & 4545.81 & $5,760.71$ & 3120 & $3,327.98$ & 7024 & 5911.02 \\
\hline $1983-84$ & 5784.25 & $6,225.13$ & 5461 & $3,594.88$ & 9662 & 5908.73 \\
\hline $1984-85$ & 6921.28 & $6,390.89$ & 5518 & $3,681.55$ & 8159 & 5894.23 \\
\hline $1985-86$ & 6406.52 & $6,446.44$ & 4034 & $3,709.63$ & 6444 & 5888.01 \\
\hline $1986-87$ & 6629.59 & $6,464.60$ & 4488 & $3,718.70$ & 6928 & 5885.83 \\
\hline $1987-88$ & 5476.84 & $6,470.49$ & 3523 & $3,721.63$ & 6583 & 5885.10 \\
\hline 1988-89 & 7210.16 & $6,472.39$ & 4893 & $3,722.57$ & 6945 & 5884.86 \\
\hline $1989-90$ & 5783.10 & $6,473.00$ & 3134 & $3,722.88$ & 5546 & 5884.80 \\
\hline $1990-91$ & 7802.25 & $6,473.20$ & 3430 & $3,722.98$ & 4499 & 5884.77 \\
\hline $1991-92$ & 4851.17 & $6,473.26$ & 2902 & $3,723.01$ & 6122 & 5884.76 \\
\hline $1992-93$ & 6066.48 & $6,473.28$ & 4188 & $3,723.02$ & 7065 & 5884.76 \\
\hline $1993-94$ & 4967.78 & $6,473.29$ & 3480 & $3,723.02$ & 7169 & 5884.75 \\
\hline 1994-95 & 3657.02 & $6,473.29$ & 2416 & $3,723.02$ & 6761 & 5884.75 \\
\hline $1995-96$ & 4966.09 & $6,473.29$ & 3588 & $3,723.02$ & 7394 & 5884.75 \\
\hline $1996-97$ & 5091.76 & $6,473.29$ & 3536 & $3,723.02$ & 7107 & 5884.75 \\
\hline $1997-98$ & 3338.90 & $6,473.29$ & 2444 & $3,723.02$ & 7491 & 5884.75 \\
\hline $1998-99$ & 4666.32 & $6,473.29$ & 3764 & $3,723.02$ & 8255 & 5884.75 \\
\hline $1999-00$ & 3795.30 & $6,473.29$ & 2919 & $3,723.02$ & 7871 & 5884.75 \\
\hline $2000-01$ & 3854.63 & $6,473.29$ & 3162 & $3,723.02$ & 8395 & 5884.75 \\
\hline 2001-02 & 4674.99 & $6,473.29$ & 3168 & $3,723.02$ & 6935 & 5884.75 \\
\hline $2002-03$ & 3119.85 & $6,473.29$ & 2487 & $3,723.02$ & 8158 & 5884.75 \\
\hline 2003-04 & 3767.85 & $6,473.29$ & 3076 & $3,723.02$ & 8357 & 5884.75 \\
\hline 2004-05 & 3941.16 & $6,473.29$ & 3310 & $3,723.02$ & 8595 & 5884.75 \\
\hline 2005-06 & 4258.77 & $6,473.29$ & 3444 & $3,723.02$ & 8276 & 5884.75 \\
\hline
\end{tabular}

These calculated values are given in Table 1. Actual and optimal level of harvests, stocks, and efforts for the period 1981-1982 to 2005-2006 are shown respectively in Figures 1, 2, and 3.

Table 1. Actual and Optimal Stock, Harvest \& Effort Levels of Bangladesh Trawl Shrimp Fishery

Source: Actual values are presented from Ray and Khan (2003) \& MFSMUC (2007) and optimal values are calculated by the author using the model. 


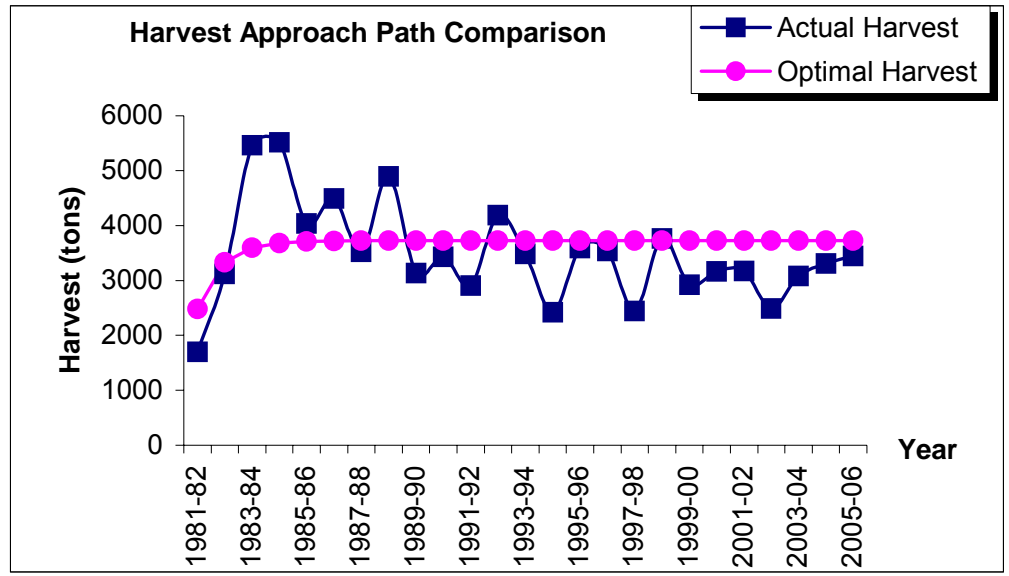

Figure 1. Harvest Approach Path Comparison

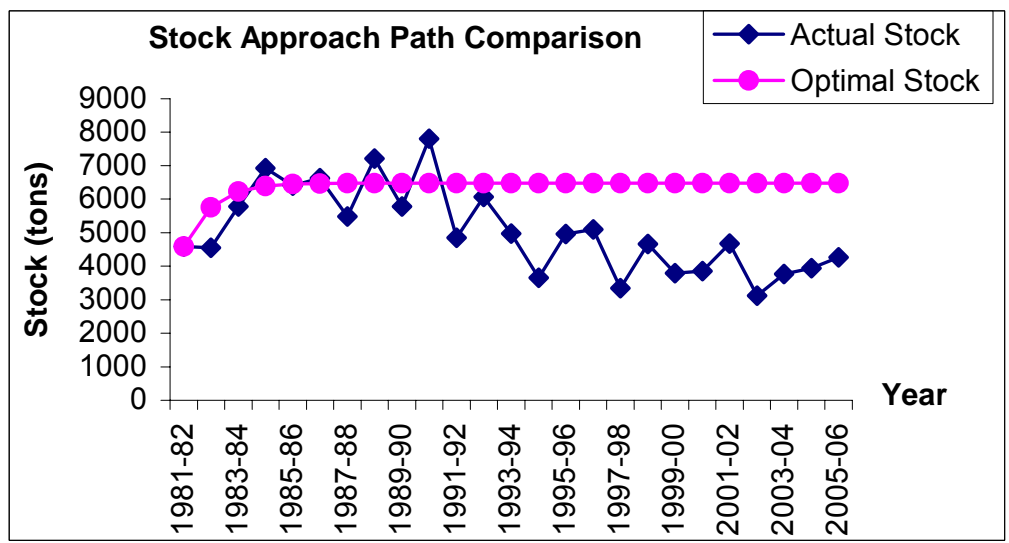

Figure 2. Stock Approach Path Comparison

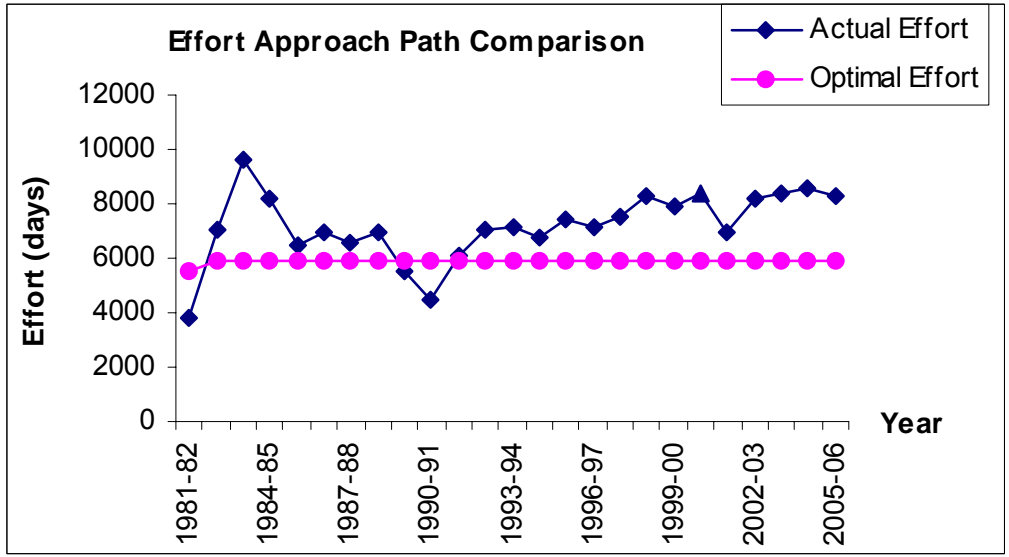

Figure 3: Effort Approach Path Comparisons 


\section{M.S. Uddin Khan}

\section{RESULTS AND DISCUSSION}

With actual shrimp stock (1981-82) and an initial guess, the solver optimizes the sum of PVNB over the period when cost parameters, demand parameters, intrinsic growth rate, carrying capacity, discount factors are given as constant. Results of Non-linear dynamic optimization model are provided in Table-1.

We find from Table-1 that system reaches at steady state very quickly. It takes only nine (9) years. Similar studies on Northern Anchovy Fishery of California (Kolberg, 1993), Canadian Northern Cod Fishery (Grafton et al, 2000) show that the system takes much longer time for reaching steady state. It implies that the Bangladesh shrimp fishery system is under favourable condition in the sense that it would require much less time to recover stock by implementing corrective measures.

The optimal stock and harvest level attained steady state in the year 1991-92 at 6473 metric tons and 3723 metric tons respectively. But comparison with the actual and current harvests during the period of study indicates the fact that current harvest level is much lower than the level of optimal harvest. Lower level of actual harvest may be explained by the fact that overfishing during the period 1983-84 to $1986-87$ may have had some consequences on population dynamics of the species.

Approach paths of harvest, stock and effort, are depicted in Figures-1 to 3 . Harvests and stocks are initially higher than the steady state situation, but gradually decline below the optimum steady state level. Not only that, it also clearly reveals that the gap between actual and optimal values keeps increasing. On the contrary, in case of effort, it is much higher both in the initial and later phases but around steady state level in between. It clearly implies that the higher level of effort causes overfishing which, in turn, causes lower stock. As a consequence, even higher level of effort in later years does not get adequate quantity of catch. This is obviously alarming and demands immediate attention of policy makers and administrations. In order to protect the resource from depletion or other catastrophic collapse, immediate measures must be taken. Scientific approach must be adopted for managing this resource.

\section{CONCLUSION}

The results of the study presented in this paper conclude the following:

(a) Bangladesh marine shrimp fishery is not managed and utilized optimally.

(b) Present condition of high effort, less harvest and less biomass stock indicates that the danger of depletion of the resource cannot be ruled out.

(c) Steady state is found to be attained by the system very quickly. It implies that marine shrimp fishing of Bangladesh would take less time and cost to recover from the sub-optimal level if corrective measures are taken.

\section{LITERATURE CITED}

BBS (Bangladesh Bureau of Statistics), 1999. 1998 Statistical Year Book of Bangladesh, BBS, GOB, Dhaka.

BOBP, 1993. Studies of Interactive Marine Fisheries of Bangladesh, BOBP/WP/89, Bay of Bengal Programme, Madras, India.

BOBP, 1997. Report of the National Workshop on Fisheries Resources Development and Management in Bangladesh, BOBP/REP/74, Bay of Bengal Programme, Madras, India.

Butterworth, D. S. 1980. The Value of Catch-Statistics-Based Management Techniques for Heavily Fished Pelagic Stocks, with Special Reference to the Recent Decline of the Southwest African Pilchard Stock, International Council for Southeastern Atlantic Fisheries (ICSEAF) Colln. Scient. Pap. (Part-II), pp. 69-84.

Clark, C. W. 1990. Mathematical Bioeconomics: The Optimal Management of Renewable Resources, $\left(2^{\text {nd }}\right.$ ed. $)$, John Wiley and Sons, New York.

Conard, J. M. 1999: Resource Economics, Cambridge University Press, New York. 
DOF (Department of Fisheries) 1999. A Brief on Department of Fisheries, Bangladesh, DOF, GOB, Dhaka.

DOF (Department of Fisheries) 2000. "Report on Status of the Demersal Fishery Resources of Bangladesh", Paper presented at the National Consultative Workshop on Sustainable Development of Coastal Fish Stocks (ADB-RETA 5766 Project) held at Dhaka, Bangladesh during October 3-5, 2000 as Organised by DOF \& ICLARM.

EPBB (Export Promotion Bureau of Bangladesh) 2000. Export from Bangladesh: 1972-73 to 1998-99, GOB, Dhaka.

Food and Agriculture Organization [FAO] 1979. "Mammals in the Sea", Vol. 1, Rome.

Grafton, R. Q., Sandal L. K. and Steinshamn, S. I. 2000. "How to Improve the Management of Renewable Resources: The Case of Canada's Nothern Cod Fishery", American Journal of Agricultural Economics 82(3), 570-580.

Johnston, R. J., and Sutinen, J. G. 1996. "Uncertain Biomass Shift and Collapse: Implications for Harvest Policy in the Fishery", Land Economics, 72(4), pp.500-518.

Khan, A. A. 2000. "Report on Status of the Demersal Fishery Resources of Bangladesh", Paper presented at the National Consultative Workshop on Sustainable Development of Coastal Fish Stocks (ADB-RETA 5766 Project) held at Dhaka, Bangladesh during October 3-5, 2000 as Organised by DOF \& ICLARM.

Khan, M. S. and Hoque, M. S. 2000. "Bioeconomic Modeling: Bangladesh Shrimp Fishery", Paper Presented at the International Seminar in Malaysia.

Khan, M. S. and Hoque, M. S. 2000a. "Fleet Operational Dynamics: Bangladesh" Paper Presented at the International Seminar in Malaysia.

Khan, M. G., Humayun, M., Mustafa, M. G., Mansura, B., Paul, S. C. and Sada, M. N. U. 1983. Results from the $15^{\text {th }}$ Cruise of the R. V. Anusandhani to the Demersal Fishing Grounds of the Northern Bay of Bengal (Bangladesh), Marine Fisheries Research Management and Development Project, Chittagong.

Lamboeuf, M. 1987. Bangladesh Demersal Fish Resources of the Continental Shelf, FAO/BGD. F1: DP/BGD/80/025/1, Marine Fisheries Research, Management and Development Project.

Marine Fisheries Survey Management Unit Chittagong (MFSMUC) 2007. Report on Marine Fisheries in Bangladesh, Chittagong.

Murphy, G. I. 1977. "Clupeoids", in Gulland, J. (Ed.), "Fish Population Dynamics”, Wiley-Interscience, New York, pp. 283-308.

Mustafa, M. G. and Khan, M. G. 1993. "The Bottom Trawl Fishery", In: Studies of Interactive Marine Fisheries of Bangladesh, BOBP/WP/89, pp. 89-106.

Penn, J. W. 1983. "An Assessment of Potential Yield from the Offshore Demersal Shrimp and fish Stock in Bangladesh Waters (Including Comments on the Trawl Fishery 1981-1982). A Report Prepared for the Fisheries Advisory Service (Phase-II) Project, Rome, FAO, F1: DP/BGD/ 81/034, Field Document 4: p.22.

Rashid, M. H. 1983. "Mitsui-Taiyo Survey 1976-1977 by the Survey Research Vessels MV Santamonica and MV Orion-8 in the Marine Waters of Bangladesh", Research / Survey of Marine Fisheries under the Directorate of Fisheries, Govt. of Bangladesh, Marine Fisheries Bulletin.

Ray, A. K. and Khan, M. S. U. 2003. "Estimating Some Parameters of Trawl Shrimp Fishery in Bangladesh", Indian Journal of Fisheries 50(3), 251-257.

Ruitenbeek, H. J. 1996. "The Great Canadian Fishery Collapse: Some Policy Lessons”, Ecological Economics, 19(2), 103-106.

Saetre, R. 1981. Surveys on the Marine Fish Resources of Bangladesh, Nov.-Dec 1979 and May 1980 Reports on Surveys with the R. V. Dr. Fridtjof Nansen, Institute of Marine Research, Bergen.

Saville, A. [ed.] 1980. The Assessment and Management of Pelagic Fish Stocks, Cons. Intern. Expl. Mer., Rapp. et Proc. -Verb. des Reunions 177.

Sindermann, C. J. 1979. Status of the Northwestern Atlantic Herring Stocks of Concern to the United States, U. S. N. O. A. A., National Marine Fisheries Service, Northeast Fisheries Center, Highlands, New Jersey, Tec. Services Rel. No. 23.

VanZalinge, N. P. 1986. "The Bangladesh Shrimp Resources", Field Document, BGD/80/025, DOF, p.17.

West, W. Q. B. 1973. "Fishery Resources of the Upper Bay of Bengal" Indian Ocean Programme, Indian Ocean Fisheries Commission, Rome, FAO, IFOC/DEV/73/28.

White, T. F. and Khan, M. G. 1985. "Marine Fishery Resources Survey: Demersal Trawling Survey", Cruise Report No.1, FAO/BGD/80/025/CRI, Chittagong, Bangladesh, p.67. 